\title{
The Magnitude of Menu Costs: A Structural Estimation
}

\author{
Andrea Stella
}

Federal Reserve Board

December 6, 2013

The leading theories on monetary policy non-neutrality require some degree of price rigidity, which is often introduced by assuming fixed costs of price adjustment, also known as menu costs. Empirical evidence on the existence of such menu costs is scarce. Using weekly data on prices, costs and units sold by a supermarket chain, I estimate a discrete-choice dynamic model of a multi-product firm facing menu costs with a moment inequalities approach. This empirical methodology allows me to estimate two types of fixed costs of price adjustment: costs that are independent of the number of items that change prices and costs that are incurred at each item's price change. I find that both types of menu costs exist and are substantial. The total cost from changing prices is estimated to be bounded between $0.22 \%$ and $0.59 \%$ of revenues and between $11.05 \%$ and $29.32 \%$ of net margins, depending on the specification. The first type of fixed cost accounts for up to $85 \%$ of this expense, pointing to substantial economies of scope in price setting.

JEL Classifications: E30, E31, E32, L11, L81

Keywords: menu costs, moment inequalities, multi-product firms

\footnotetext{
*The views in this paper are solely the responsibility of the author and should not be interpreted as reflecting the views of the Board of Governors of the Federal Reserve System or of any other person associated with the Federal Reserve System. This paper is based on the first chapter of my 2012 Harvard University Ph.D. dissertation. I would like to thank my advisors Alberto Alesina, Greg Mankiw and James Stock for guidance and support. I wish to thank also Shai Bernstein, Lorenzo Casaburi, Stefano Giglio, Ed Knotek, David Laibson, Jacob Leshno, Eduardo Morales, Ariel Pakes, Mike Sinkinson, Ugo Troiano and numerous seminar participants for useful feedback and suggestions. Kevin Binns, Teyanna Munyan and Rebecca Spavins provided excellent research assistance. Special thanks go to Pinelopi Goldberg and Rebecca Hellerstein for sharing their dataset. All errors are my own.
} 


\section{Introduction}

The leading theories on the monetary policy transmission mechanism require some degree of price rigidity. The most common way to introduce price rigidity in a rigorous way in macroeconomic monetary models involves fixed costs of price adjustment, also known as menu costs. The monetary economics literature makes an extensive use of menu costs ${ }^{1}$, but there have been only a few attempts at estimating actual menu costs. The first generation of menu cost models ignored price setting interactions by assuming that each firm sells only one product and was rejected by the empirical evidence. ${ }^{2}$ Midrigan (2011) shows that economies of scope in price setting can help improve the empirical fit of menu cost models and achieve high degrees of monetary non-neutrality. These theoretical results beg the empirical question of whether such price setting interactions exist in reality.

I estimate a dynamic multi-product firm model using supermarket scanner data on weekly sales, prices and costs. I combine a structural model of the dynamic pricing decision of a supermarket with an empirical demand model for differentiated products. On the one hand, I estimate demand following Berry, Levinsohn, and Pakes (1995) with a random coefficients model. On the other hand, I model the pricing decision of the supermarket as a dynamic unconstrained maximization of the discounted stream of profits. A manager is responsible for choosing prices for all the products belonging to the same category in order to maximize the profits of the supermarket. Following Sheshinski and Weiss (1992), I model two types of menu costs: a "common menu cost" that is paid independently of how many price changes are made and a "item menu cost" that is proportional to the number of price changes. I find that both types of menu costs are statistically and economically significant. The total cost from changing prices in the period of my analysis is estimated to be bounded between $0.22 \%$ and $0.59 \%$ of revenues and between $11.05 \%$ and $29.32 \%$ of net margins, depending on the specification. The "common menu cost" accounts for up to $85 \%$ of this expense, pointing to substantial economies of scope in price setting.

This paper improves on previous estimates in two dimensions. First, I estimate menu costs using a multi-product firm model, whereas all previous structural estimates were done with single-product firm models. To the best of my knowledge, I am the first to estimate both fixed costs that are independent of the number of items that change prices and fixed costs that are incurred at each item's price change. The recent theoretical

\footnotetext{
${ }^{1}$ Barro (1972), Sheshinski and Weiss (1977) and Mankiw (1985) were the first to consider the impact of fixed costs of price adjustment on price stickiness and many recent papers in the macro literature follow their approach. Some examples are Gertler and Leahy (2008), Dotsey, King, and Wolman (2009), Nakamura and Steinsson (2010), Midrigan (2011), Eichenbaum et al. (2011), Kehoe and Midrigan (2011).

${ }^{2}$ Some notable examples are Golosov and Lucas (2007) and Klenow and Kryvtsov (2008)
} 
literature shows that economies of scope in price setting are crucial for matching the empirical facts about prices and produce high degrees of monetary non-neutrality. ${ }^{3}$ If a firm sells many products and faces economies of scope in price setting, once the price of a product is changed the firm can change the price of the other products with small additional costs. This is consistent with the observation of many small individual price changes and a high average price change that is typical of most microdata on individual prices. Additionally Midrigan (2011) shows that with economies of scope in price setting high degrees of monetary non-neutrality can be achieved with menu costs around $0.34 \%$ of revenues, which is consistent with my estimates.

Second, I use moment inequalities estimation ${ }^{4}$, which allows me to deal with the dimensionality problem caused by a multi-product firm setting. The choice set of a firm that decides every week whether to change the price of $N$ products contains $2^{N}$ possible choices, which makes it computationally infeasible to use traditional discrete choice empirical methods. My estimation procedure is based on the simple assumption that the agent chooses strategies that according to her own expectations will lead to higher profits than feasible alternatives. A supermarket manager will change prices only if the cost of doing so is lower than the increased profits; conversely, she will not change prices if the costs are higher. By estimating a demand model, I am able to predict how sales, and therefore profits, would have changed if the manager had made different pricing decisions and therefore provide bounds for the magnitude of menu costs the manager faces.

My results reveal two interesting features of menu costs. First, the estimated menu costs are substantial and are consistent with the values shown by the theoretical literature to be large enough to produce high degrees of monetary non-neutrality. ${ }^{5}$ This result provides empirical support for the existence of menu costs and therefore for the ability of state dependent pricing models to replicate the main features of the dynamic response of real variables to monetary policy shocks. Second, I find substantial economies of scope in price setting and therefore provide empirical evidence for Midrigan (2011) and more generally for the second-generation of state dependent pricing models, which have been able to revive the interest in menu costs as a possible explanation for the observed monetary non-neutrality.

The empirical evidence shows that monetary policy has real effects, at least in the

\footnotetext{
${ }^{3}$ Some notable examples are Midrigan (2011) and Alvarez and Lippi (2012)

${ }^{4}$ My empirical strategy draws extensively from Pakes (2010), Pakes et al. (2011) and Morales et al. (2011).

${ }^{5}$ Midrigan (2011) uses menu costs around $0.34 \%$ of revenues. In the multi-sector model by Nakamura and Steinsson (2010) menu costs are less than $0.5 \%$ in most sectors.
} 
short run ${ }^{6}$, but we still do not completely understand why. The prices collected by the Bureau of Labor and Statistics to compute the CPI have been shown to display significant price rigidity $^{7}$ : median price duration is around 3 quarters. A class of models that can produce significant price rigidity is represented by state dependent pricing models; firms face a fixed cost of price adjustment, also known as menu cost, which makes less frequent the adjustment of prices. Caplin and Spulber (1987) show that in state dependent pricing models there is a selection effect: the firms that change prices are those that are far from their optimal price. This selection effect substantially weakens the real effects of monetary policy. Golosov and Lucas (2007) expand on this intuition by calibrating a heterogenous agents model with firms facing fixed costs of price adjustment using microdata on prices from Klenow and Kryvtsov (2008) and find that monetary non-neutrality cannot be produced by menu cost models calibrated on the US economy.

Midrigan (2011) is the first to consider a multi-product setting in which firms produce and sell many products and face economies of scope in adjusting prices; price setting interactions combined with a fat-tailed distribution of cost shocks substantially weaken the selection effect described by Golosov and Lucas so that monetary policy can have large real effects. Some evidence supporting this new approach of modeling menu costs comes from Klenow and Kryvtsov (2008), who compare the performance of time dependent and first generation state dependent pricing models and find that neither the former nor the latter satisfactorily match the data; they conclude that second generation state dependent models, like Midrigan (2011), are broadly consistent with the empirical facts. In this paper, I provide a formal empirical test for the existence of economies of scope for multi-product firms. I find that menu costs exist and more importantly that economies of scope play an important role in price setting. These results provide empirical support for the second generation of state dependent pricing models that have been so successful in explaining monetary non-neutrality.

The rest of the paper is organized as follows. Section 2 describes the dynamic problem of the retailer and the model of demand. Section 3 explains the estimation procedure; I first estimate a discrete-choice model of demand and then use the moment inequalities approach to estimate the parameters of interest. Section 4 explains how I construct confidence intervals. Section 5 introduces the Dominick's dataset and presents some summary statistics. Section 6 contains the main results of the paper. Finally, in Section 7 I compare

\footnotetext{
${ }^{6}$ See Christiano et al. (1996), Cochrane (1998), and Romer and Romer (2004).

${ }^{7}$ Some notable examples of studies on microprice data are Hosken et al. (2000), Bils and Klenow (2004), Kackmeister (2007), Klenow and Kryvtsov (2008), Nakamura and Steinsson (2008) and Gagnon (2009).
} 
my results with the previous literature and in Section 8 I conclude.

\section{Theory}

\subsection{Pricing Decision}

In this section, I present a model of the pricing decision made by supermarket managers. Supermarkets provide an optimal setting for studying price setting interactions as they are a perfect example of multi-product firm. I focus on a product category and model the decision made by the manager responsible for setting prices in order to maximize profits; supermarket profits depend on the prices that are charged for the products sold (the vector $\mathbf{p}$ in my model), the demand for the products $(\mathbf{q})$ and the wholesale costs $(\mathbf{c})$ that the supermarket pays for the products. In the next section I explain in detail how I model demand.

Assumption 1 The supermarket is a local monopolist.

This assumption is consistent with the evidence that consumers do not shop across stores on a product-by-product basis. ${ }^{8}$ Chintagunta et al. (2003) present evidence that stores collect all competitors' prices only once per year and on a weekly basis they follow competitors' action in a very limited way. ${ }^{9}$ Since I consider deviations from decisions on prices of a few products at a time, the assumption that pricing decisions do not depend on the behavior of competitors seems to be reasonable and simplifies the empirical analysis. ${ }^{10}$

\footnotetext{
${ }^{8}$ Slade (1995) and Chintagunta et al. (2003) provide some anecdotal evidence. Slade (1995), for instance, interviewed grocery-chain marketing managers who claimed that according to their experience less than $10 \%$ of households visit several stores within the same week to search for the lowest-priced product. Dreze et al. (1994) run an experiment in a random subsample of stores belonging to the Dominick's Finer Foods chain by changing prices across 26 product categories for 16 weeks; they find that the price changes had no impact on store traffic after a three months period.

${ }^{9}$ Chintagunta et al. (2003) report: "We also conducted telephone interviews with Chicago area store managers and our findings were consistent with this claim. Stores do condition on their competitors actions in a limited way by collecting a weekly sample of half a dozen SKUs from the local competitors entire store offerings. However, this behavior seems more consistent with competition on overall offerings rather than on a category-by-category basis. Stores collect a fullbook of about 600 to 1000 prices from local competitors annually. This practice is not likely to generate inter-store competition at the category level and weekly frequency we consider in our analysis". Slade (1998) also states: "The anecdotal evidence therefore favours a model where competition is among brands within a store. This does not mean, however, that chains fail to compete. Rather it implies that chains compete via their total offerings rather than through individual items such as saltine crackers"
}

${ }^{10}$ Slade (1998), Besanko et al. (1998), Chintagunta et al. (2003), Montgomery (1997) and others make 
Assumption 2 The category manager decides every week the regular prices of all the products within a category taking as exogenously determined the calendar of promotions and the wholesale prices.

The second assumption derives directly from the procedures followed by supermarkets in setting prices. It has been well documented by the marketing literature that pricing decisions in the retail industry are made by category managers who are responsible for setting the prices of all the products within a category in order to maximize the firm's profits; ${ }^{11}$ there is plenty of evidence that this is the organizational structure of Dominick's as well. For these reasons, I assume that the category manager is the economic agent responsible for the price setting and therefore the fixed costs of price adjustment. ${ }^{12}$

A striking feature of supermarket pricing is represented by promotions, which happen frequently in every category of products. Chintagunta (2003) report that in the Dominick's supermarket chain promotions are funded almost entirely by manufactures and the timing is determined by the retailer in advance so as to allow the category managers to make the pricing decisions conditional on the promotion calendar. Consequently, category managers have very limited power on the promotional schedule, and simply take it as given when they set regular prices. From here on, I will use "price" and "regular price" interchangeably and it will be understood that promotional price changes are not used in the moment inequalities estimation. ${ }^{13}$

Wholesale prices represent the costs that the supermarket pays for the products that it sells, the vector c in my framework. Villas-Boas (2007) analyzes the vertical relationship in the supermarket industry and finds that manufacturers price at marginal cost, whereas the retailer sets prices with an unconstrained profit maximization. ${ }^{14}$ Given this evidence, I assume that the supermarket is a price-taker in its relationship with suppliers and the category manager makes pricing decisions taking the wholesale prices $\mathbf{c}$ as exogenously determined.

When a manager decides to change a regular price, he has to pay a fixed cost. This fixed cost consists of two components. The first component does not depend on the number of

this same modeling assumption and treat the retailer as a local monopolist.

${ }^{11}$ Basuroy et al. (2001) provides an analysis of category management in the supermarket industry.

${ }^{12}$ Aguirregabiria (1999) shows that the inventory and pricing decisions can be mutually dependent in presence of fixed ordering costs and nominal rigidities. As discussed by Goldberg and Hellerstein (2013), for legal reasons the supermarkets where the data were collected were not allowed to keep inventories of the product I focus on, beer, and therefore I can ignore the inventory choice in my analysis.

${ }^{13}$ However, promotional price changes are kept for the demand estimation.

${ }^{14}$ Some more evidence on the vertical relationship in the supermarket industry is provided by Sudhir (2001) and Kadiyali et al. (2000). 
price changes. The classical example is about a restaurant manager who wants to change the price of one or more items in the restaurant menu; new menus will have to be printed and the cost of printing does not depend on how many prices are changed. ${ }^{15}$ The second component of the fixed cost is proportional to the number of price changes and represents a cost that has to be paid for each price change. Anderson et al. (2012) provides some anecdotal evidence on the pricing procedures that suggest both significant fixed costs of price adjustment and economies of scope in price setting. They find that most regular price changes are due to permanent changes in the wholesale costs; when wholesale costs are changed, the supermarket chain is noticed in advance and the category manger decides whether to change the regular price of the product; if the decision is to change the price, the category manager needs to seek the approval of a special team that reviews the price change to make sure that it complies with the firm's pricing rules. If the price change is approved, it is sent to the retail stores and the price stickers are physically changed. This process takes approximately two weeks. Once the category manger decides to get this process started, it may as well consider to change more than one price at the same time. However, a fixed cost needs clearly to be paid also for each price change, both in terms of managerial costs and in terms of physical costs.

Going back to my model, I posit two types of fixed costs of price adjustment: costs that are independent of the number of items that change prices and costs that are incurred at each item's price change. The period $t$ profits for product category $P$ are therefore given by:

$$
\pi_{t}^{P}=\left[\mathbf{p}_{t}-\mathbf{c}_{t}\right] \cdot \mathbf{q}_{t}-\eta_{1} \cdot \mathbf{1}\left(\exists j: p_{j t} \neq p_{j t-1}\right)-\sum_{j=1}^{J} \eta_{2} \cdot \mathbf{1}\left(p_{j t} \neq p_{j t-1}\right)
$$

where $\mathbf{q}_{t}$ is the vector of quantities sold for the $\mathrm{J}$ goods in category $P, \mathbf{p}_{t}$ is the vector of prices, $\mathbf{c}_{t}$ is the vector of marginal costs, $\eta_{1}$ is the "common menu cost", which is independent of the number of price changes and $\eta_{2}$ is the "item menu cost", which is incurred at each price change. The category manager faces a dynamic optimization problem and decides each period a vector of prices $\mathbf{p}_{t}$ in order to maximize the discounted sum of profits given his information set in period $t, \mathcal{J}_{t}$, and his subjective expectations, $\mathcal{E}$ :

$$
\max _{\left\{\mathbf{p}_{t} \in \mathcal{B}_{t}\right\}} \mathcal{E}_{t}\left[\sum_{\tau=t}^{\infty} \gamma^{\tau} \pi_{\tau}^{P} \mid \mathcal{J}_{t}\right]
$$

\footnotetext{
${ }^{15}$ This is how the name "menu cost" originated.
} 
where $\gamma$ is the discount factor. Each price $p_{j t}$ is chosen among the values in set $\mathcal{B}_{j t}$. During promotions $\mathcal{B}_{j t}$ is restricted to the predetermined promotional price, whereas when the product is not on promotion the manager can choose any positive real number and $\mathcal{B}_{j t}$ coincides with $\mathcal{R}^{+}$. I will make assumptions on the agent's expectations $\mathcal{E}$ in Section 3.4.

\subsection{Demand}

To estimate menu costs with moment inequalities I need to compute counterfactuals. Computing a counterfactual consists in finding out how much the supermarket would have made in profits if it had charged a different price vector. I therefore need to estimate the demand of the products in the categories I choose to analyze. In my notation, I need to estimate $\mathbf{q}_{t}$. Once I have a way to forecast demand, I can then compute counterfactuals and moment inequalities.

Estimating demand for differentiated products poses mainly two challenges. First, the demand for a product does not depend only on its own characteristics and price, but also on those of other products that are perceived as substitutes by the consumers. For this reason a simple linear model that relates the market share of a product to its own characteristics would be too restrictive. On the other hand, we could specify a set of demand equations, one for each product, and have the demand for a product depend on its own price and the price of the other products; the problem with this approach is that if there are many products, the number of parameters to estimate would be too high. Furthermore a simple linear model would not be able to control for the heterogeneity in consumer tastes.

A way to solve the dimensionality problem is to make some functional form assumptions; in the logit demand model, for instance, products are projected onto a space of characteristics and this simplifies the estimation. The drawback is that the functional form assumptions in most cases drive the results of the estimation; in the case of the logit model, the estimated own- and cross-price elasticities depend only on the price and the market share, implying that the lower is the price the lower will be the elasticity and that consumers substitute between different products in proportion to market share, regardless of the characteristics of the products. These properties of the logit model are unrealistic in most cases.

The second challenge in estimating demand is represented by the endogeneity of prices. There are almost always some product characteristics that are hard to measure, but are correlated with prices and if not included in the estimation will bias the price coefficients. Another possible source of endogeneity is the omission of a control for advertisement; 
manufacturers run national TV ads and supermarkets engage in local advertisement; these marketing efforts must be correlated with the retail prices.

Following the recent empirical IO literature, I use a random-coefficients logit model, ${ }^{16}$ which captures the substitution patterns between products in a nontrivial way and whose estimation controls for the endogeneity of prices. The demand model I adopt is static: since I will focus on the beer sales of the Dominick's supermarkets and, according to the industry lore, beer products are typically consumed within a few hour of their purchase, I am not worried of consumer inventory behavior or other dynamic demand issues. ${ }^{17}$

I observe $t=1, \ldots, T$ markets, each with $i=1, \ldots, I$ consumers, where a market $t$ is a store-week combination. In this model when a customer visits the supermarket he is allowed to buy and consume only one product within the product category of analysis, but he can also choose not to buy any product in that category. I assume that the indirect utility of consumer $i$ from consuming product $j$ in market $t$ takes a quasi-linear form:

$$
u_{i j t}=\alpha_{i}\left(y_{i}-p_{j t}\right)+x_{j t} \beta_{i}+\xi_{j t}+\epsilon_{i j t}
$$

where $y_{i}$ is the income of consumer $i, p_{j t}$ is the price of product $j, x_{j t}$ is a vector of observed characteristics, $\xi_{j t}$ captures the unobserved product characteristic and $\epsilon_{i j t}$ is a mean zero stochastic term. Consumer preferences are represented by the random coefficients $\alpha_{i}$ and $\beta_{i}$ that can be decomposed in a constant component and an individual unobserved component $v_{i}$, which is distributed according to a standard multivariate normal distribution. The matrix of parameters $\Sigma$ allows each component of $v_{i}$ to have a different variance.

$$
\left(\begin{array}{c}
\alpha_{i} \\
\beta_{i}
\end{array}\right)=\left(\begin{array}{c}
\alpha \\
\beta
\end{array}\right)+\Sigma v_{i}, \quad v_{i} \sim P_{v}^{*}(v)
$$

The utility can be then decomposed in three parts: $\delta_{j t}$ is the mean utility given by product $j$ at time $t, \mu_{i j t}$ is the individual deviation from mean utility and $\epsilon_{i j t}$ is distributed

\footnotetext{
${ }^{16} \mathrm{My}$ demand model is based on Berry et al. (1995) and Nevo (2001)

${ }^{17}$ Goldberg and Hellerstein (2013) gives more details on the beer market, whereas Hendel and Nevo (2006) shows that if consumers are solving a dynamic problem, static demand models may produce biased estimates.
} 
according to a Type I extreme- value distribution:

$$
\begin{aligned}
u_{i j t} & =\alpha_{i} y_{i}+\delta_{j t}\left(x_{j t}, p_{j t}, \xi_{j t} ; \theta_{1}\right)+\mu_{i j t}\left(x_{j t}, p_{j t}, v_{i} ; \theta_{2}\right)+\epsilon_{i j t} \\
\delta_{j t} & =x_{j t} \beta-\alpha p_{j t}+\xi_{j t} \\
\mu_{i j t} & =\left[\begin{array}{ll}
-p_{j t} & x_{j t}
\end{array}\right] \Sigma v_{i}
\end{aligned}
$$

Finally consumers can choose not to buy any product and consume the outside option; both the mean utility and the individual deviation from mean utility of the outside good are normalized to zero:

$$
u_{i 0 t}=\alpha_{i} y_{i}+\epsilon_{i 0 t}
$$

Having derived the utility of purchasing one unit of product $j$ at time $t$ for individual $i$, it is possible to compute the share of customers who are going to choose product $j$ over all the other products and the outside good. Assuming ties occur with zero probability, the market share of product $j$ in market $t$ is:

$$
\begin{aligned}
s_{j t}\left(x_{j t}, p_{j t}, \xi_{j t} ; \theta_{2}\right) & =\int_{A_{j t}} d P_{\epsilon}^{*}(\epsilon) d P_{v}^{*}(v) \\
A_{j t} & =\left\{\left(v_{i}, \epsilon_{i 0 t}, \ldots, \epsilon_{i J t}\right) \mid u_{i j t} \geq u_{i l t} \quad \forall l=0,1, \ldots, J\right\}
\end{aligned}
$$

The price elasticities will therefore be:

$$
\frac{\partial s_{j t}}{\partial p_{h t}} \frac{p_{h t}}{s_{j t}}= \begin{cases}-\frac{p_{j t}}{s_{j t}} \int \alpha_{i} s_{i j t}\left(1-s_{i j t}\right) d P_{v}^{*}(v) & \text { if } j=h \\ \frac{p_{h t}}{s_{j t}} \int \alpha_{i} s_{i j t} s_{i h t} d P_{v}^{*}(v) & \text { if otherwise }\end{cases}
$$

Substitutions patterns are not predetermined by the functional form or some other assumption, but depend both on the sensitivity to prices $\alpha$ and on the product and consumer characteristics. Brands with similar characteristics are more substitutable and the degree of substitutability is estimated instead of assumed. 


\section{Estimation Procedure}

\subsection{First Stage: Demand Estimation}

I estimate the random coefficients demand model following the methodology developed by Berry et al. (1995) and Nevo (2001). First, for a given set of parameters $\theta$, I solve for the system of equations:

$$
s_{j t}\left(\delta_{t} ; \theta_{2}\right)=S_{t} \quad t=1, \ldots, T
$$

where $s(\cdot)$ is defined as (5) and $S_{t}$ are the observed market shares. Products' market shares are calculated with respect to the potential market which is defined as the number of customers who visit the store in a period. ${ }^{18}$ I approximate the integral in (5) with a smooth simulator; given a set of draws from $P(v)$ the approximation is:

$$
s_{j t}=\frac{1}{I} \sum_{i=1}^{I} \frac{\exp \left[\delta_{j t}+\sum_{k=1}^{K} x_{j t}^{k} \sigma_{k} v_{i}^{k}\right]}{1+\sum_{m=1}^{J} \exp \left[\delta_{m t}+\sum_{k=1}^{K} x_{j t}^{k} \sigma_{k} v_{i}^{k}\right]}
$$

Once I obtain the estimates for $\delta_{t}$ from (6), I can compute the unobserved characteristic $\xi_{t}$ :

$$
\xi_{j t}=\delta_{j t}\left(S_{t} ; \theta_{2}\right)-\left(x_{j t} \beta+\alpha p_{j t}\right)=\omega_{j t}
$$

Given a set of instruments $Z$ such that:

$$
E\left[Z_{m} \omega(\theta)\right]=0 \quad m=1, \ldots, M
$$

I employ two-step GMM estimation and therefore the estimate is

$$
\hat{\theta}=\underset{\theta}{\operatorname{argmin}} \omega(\theta)^{\prime} Z \Phi^{-1} Z^{\prime} \omega(\theta)
$$

\footnotetext{
${ }^{18} \mathrm{I}$ observe the number of customers that enter the supermarket every week and I assume that each customer can choose whether to buy one beer product or not. The market size is therefore the number of customers who visit the store in a period.
} 
Product and time fixed effects are included in the observed characteristics of the products and therefore the unobserved characteristic $\xi_{j t}$ reduces to a week-store specific deviation from the mean valuation of the product. In order to estimate jointly the constant preference parameters $\alpha$ and $\beta$ and the product fixed effects I follow the procedure described by Nevo (2001). Let's define $d$ the set of product dummy coefficients and $\zeta$ the unobserved product characteristics, then from (3):

$$
d=x \beta+\zeta
$$

If we assume that $\mathrm{E}[\zeta \mid x]=0$, then we can estimate $\beta$ and $\zeta$ using a minimum distance estimator:

$$
\hat{\beta}=\left(x^{\prime} V_{d}^{-1} x\right)^{-1} x^{\prime} V_{d}^{-1} \hat{d}, \quad \hat{\zeta}=\hat{d}-x \hat{\beta}
$$

Where $\hat{d}$ is estimated with the full model and $V_{d}$ is the covariance matrix of these estimates

\subsection{Instruments for Demand Estimation}

In the estimation of demand we cannot assume that prices are exogenous to the unobserved factors; it is impossible to measure all the attributes of the products and therefore there will be some unobserved attributes that influence prices and are omitted from the model. Furthermore supermarkets engage in local marketing efforts, like fliers and street ads; some products are also advertised at the national level through magazines and TV commercials. Unfortunately, I do not have a measure of these marketing efforts, which are most probably correlated with price. For these reasons price is endogenous and we need exogenous instruments for it.

Following Goldberg and Hellerstein, I use as instruments the interaction of hourly wages in the beverage industry with weekly bilateral exchange rates for foreign brands. It is reasonable to assume that these factor prices are uncorrelated with the unobserved attributes of products and the marketing efforts of the supermarket. In order to allow labor to enter the production function of each product differently, the factor prices are interacted with brand dummies to generate the instrumental variables I use in the demand estimation. $^{19}$

\footnotetext{
${ }^{19}$ Villas-Boas (2007) is the first to propose and use this type of instruments
} 


\subsection{Bounding Menu Costs}

I explain here how the moment inequality approach is applied to the estimation of menu costs. If I were to estimate menu costs using the traditional discrete choice approach, I would have to deal with a very complicated dynamic problem. Using moment inequalities I can sidestep finding a solution to the dynamic problem and estimate the menu costs using a revealed preference approach. Following Morales et al. (2011), I want to apply the Euler's perturbation method and consider a one period deviation from the observed decisions of the supermarket. Each week the manager has to decide whether to keep the prices unchanged or change them; let's call $\mathbf{d}^{T}=\left\{\mathbf{d}_{t}, \mathbf{d}_{t+1}, \ldots\right\}$ the sequence of binary decisions by the manager to change or not the prices, $\left(\mathbf{d}_{t}\right.$ is a vector of the same size as the vector of prices; the $j$-th component of $\mathbf{d}_{t}$ equals 0 if there is no price change for the $j$-th product in period $t$ and 1 if there is a price change). Let's consider a one period deviation from the strategy adopted at time $t, \mathbf{d}_{a}^{T}=\left\{\mathbf{d}_{a, t}, \mathbf{d}_{t+1}, \ldots\right\}$. Since the manager chose the observed and not the alternative strategy, it must be that according to his expectations the former would deliver a higher expected discounted stream of profits than the latter:

$$
\mathcal{E}\left[\pi\left(\mathbf{d}^{T}, \mathbf{p}^{T}\right)\right] \geq \mathcal{E}\left[\pi\left(\mathbf{d}_{a}^{T}, \mathbf{p}_{a}^{T}\right)\right]
$$

where $\pi$ is the category profits, $\mathbf{p}^{T}$ and $\mathbf{p}_{a}^{T}$ are respectively the observed and the alternative price sequences and $\mathcal{E}$ the agent's expectation operator, where the expectation $\mathcal{E}$ is conditional on the agent's information set, but to make the notation easier to read I will omit from here on the conditioning on the agent's information set. The estimation relies on the observation that in the counterfactual the manager makes a different pricing decision and therefore has to pay a different menu cost; in some deviations the counterfactual profits contain more fixed costs of price adjustment than the actual profits, whereas in other deviations the opposite is true. The difference between actual and counterfactual profits can be used to provide upper and lower bounds for the two types of menu costs.

In the empirical analysis, I use four types of moment inequalities, which I describe here through four examples. In the first example, the price of product $j$ is changed at time $t$ from $p$ to $p^{\prime}$, kept the same for a period and changed again in $t+2$ to $p^{\prime \prime}$. A one period deviation consists in not changing the price at time $t$ and then following the observed strategy, which is to keep it unchanged at time $t+1$ and change it at time $t+2$ to $p^{\prime \prime}$. In the alternative scenario the manager does not pay the menu costs at time $t$, whereas in 
reality he did. This example generates the first type of inequality:

$$
\eta_{1}+\eta_{2} \leq \mathcal{E}\left[\tilde{\pi}\left(\mathbf{d}^{T}, \mathbf{p}^{T}\right)-\tilde{\pi}\left(\mathbf{d}_{a}^{T}, \mathbf{p}_{a}^{T}\right)\right]
$$

where $\tilde{\pi}$ is equal to $\pi$ minus the menu costs paid at time $t$ and $\eta_{1}$ and $\eta_{2}$ are the two types of menu costs.

In the second example, the manager changes at time $t$ the prices of products $j$ and $h$; the cost of price adjustment equals $\left(\eta_{1}+2 \eta_{2}\right)$. In the counterfactual, the manager changes only the price of product $h$, which entails menu costs equal to $\left(\eta_{1}+\eta_{2}\right)$. In reality and in the counterfactual the firm is paying the "common menu cost", but in reality the firm is paying more "item menu cost" than in the counterfactual and therefore I can derive an upper bound for the "item menu cost", the second type of inequality:

$$
\eta_{2} \leq \mathcal{E}\left[\tilde{\pi}\left(\mathbf{d}^{T}, \mathbf{p}^{T}\right)-\tilde{\pi}\left(\mathbf{d}_{a}^{T}, \mathbf{p}_{a}^{T}\right)\right]
$$

Another possible deviation is to change the price when the manager decided not to. In the third example the manager changes the prices of products $h$ and $k$ at time $t$, but the price of product $j$ remains unchanged at $p$ until $t+2$, when it is changed to $p^{\prime \prime}$. In the counterfactual the price of $j$ is changed at time $t$ to $p^{\prime}$ and kept at $p^{\prime}$ until $t+2$, when it is changed to $p^{\prime \prime}$. In reality the menu cost is $\left(\eta_{1}+2 \eta_{2}\right)$, but in the counterfactual one more additional price is changed and therefore the menu costs are higher and equal to $\left(\eta_{1}+3 \eta_{2}\right)$. This example generates the third type of inequality, which provides a lower bound for the "item menu cost":

$$
\eta_{2} \geq \mathcal{E}\left[\tilde{\pi}\left(\mathbf{d}_{a}^{T}, \mathbf{p}_{a}^{T}\right)-\tilde{\pi}\left(\mathbf{d}^{T}, \mathbf{p}^{T}\right)\right]
$$

In the fourth and last example, at time $t$ the manager does not change any price and therefore does not pay any menu cost. In the counterfactual, the manager changes one price at time $t$ and then follows the observed strategy from period $t+1$ onwards; in the counterfactual the firm pays menu costs equal to $\left(\eta_{1}+\eta_{2}\right)$. I can then derive the fourth and last inequality inequality, which provides a lower bound for the sum of the two types of menu costs:

$$
\eta_{1}+\eta_{2} \geq \mathcal{E}\left[\tilde{\pi}\left(\mathbf{d}_{a}^{T}, \mathbf{p}_{a}^{T}\right)-\tilde{\pi}\left(\mathbf{d}^{T}, \mathbf{p}^{T}\right)\right]
$$




\subsection{Linear Moment Inequality Approach}

We can write $\mathrm{N}$ inequalities, where each inequality represents a deviation from what the supermarket actually did:

$$
\mathcal{\varepsilon} \Delta \tilde{\pi}_{a} \geq \eta_{1} \cdot S_{a, 1}+\eta_{2} \cdot S_{a, 2} \quad S_{a, 1}, S_{a, 2} \in \mathbb{Z}, a \in\{1, \ldots, N\}, \eta_{1}, \eta_{2} \in \bar{\Theta}^{C} \subseteq \mathbb{R}
$$

where $\tilde{\pi}=\left[\mathbf{p}_{t}-\mathbf{c}_{t}\right] \cdot \mathbf{q}_{t}{ }^{20} a$ indexes a deviation from the actual price decision chosen by the supermarket manager, $S_{a, 1}$ can take three values $\left\{\begin{array}{lll}-1 & 0 & 1\end{array}\right\}$ depending on whether there are price changes in both the actual and the alternative scenario, $S_{a, 2}$ is equal to the difference between the number of price changes, $\eta_{1}$ is the "common menu cost" and $\eta_{2}$ is the "item menu cost". At the true parameter $\left(\eta_{1}, \eta_{2}\right)=\left(\eta_{1}^{0}, \eta_{2}^{0}\right)$ equation $(7)$ holds for all the deviations $a$.

Following Pakes (2010), we need an assumption on the agent's expectations of profits and on the difference between the profit measure that the agent uses and the one that the econometrician uses. I assume rational expectations, which implies that the supermarket managers make the right choices on average; the average is computed across choices made by a manager, (potentially different managers), in multiple periods and with respect to multiple counterfactuals. From here on, the agent's subjective expectations $\mathcal{E}$ are going to be rational expectations, denoted by $E$. Let's call $r$ the function I use to estimate the profits and $\pi$ the agent's profit function:

$$
r=\pi+\nu
$$

The relevant difference is between $r$ and $E[\pi]$, so we can rewrite:

$$
\begin{gathered}
r=E[\pi]+\nu_{1} \\
\nu_{1}=\{\pi-E[\pi]\}+\nu
\end{gathered}
$$

The first component of $\nu_{1}$ is the expectational error by the agent and is due to uncertainty. The second component is mean independent of the information set known by the

\footnotetext{
${ }^{20}$ In other words, $\tilde{\pi}$ is the category profits minus the menu costs
} 
agent before making the decision; in my setting I have some simulation error due to the approximation via simulation of the integral in (5).

Let $\left\{z_{a, k}, k=1, . ., K\right\}$ be a set of nonnegative $K$ instruments for each $a$. At the true parameters we can write:

$$
E z_{a, k} \Delta \tilde{\pi}_{a} \geq z_{a, k} S_{a, 1} \eta_{1}^{0}+z_{a, k} S_{a, 2} \eta_{2}^{0} \quad \text { for all } k \text { and } a
$$

Since I assume that the econometrician profit function $r$ is equal to the agent's profit function $\pi$ plus some simulation error $\nu$, I can say that the difference between the econometrician's and the agent's profit functions is exogenous to the instruments of the moment inequalities estimation, $E\left(\nu \mid z_{a, k}\right)=0$. I can then write down $K$ moment inequalities that are satisfied at the true parameter:

$$
m_{k}\left(\eta_{1}^{0}, \eta_{2}^{0}\right) \geq 0 \quad \forall k \in\{1,2, \ldots, K\}
$$

where $m_{k}$ is equal to:

$$
m_{k}\left(\eta_{1}^{0}, \eta_{2}^{0}\right)=E\left[z_{a, k} \Delta \tilde{r}_{a}\right]-z_{a, k} S_{a, 1} \eta_{1}-z_{a, k} S_{a, 2} \eta_{2}
$$

The identified set $\Theta^{C}$ is the subset of points that satisfy the $K$ linear constraints in equation (9). If I define $Q(\theta)$ as :

$$
Q(\eta)=\sum_{k=1}^{K}\left(\min \left\{0, m_{k}(\eta)\right\}\right)^{2}
$$

then the identified set is the set of points $\eta \in \Theta^{C}$ solving:

$$
0=\min _{\eta \in \bar{\Theta}^{C}} Q(\eta)
$$


The empirical counterparts of (9) and (10) are:

$$
\begin{aligned}
\hat{m}_{k}\left(\eta_{1}, \eta_{2}\right) & =\sum_{a=1}^{N} \frac{z_{a, k} \Delta \tilde{r}_{a}}{N}-\sum_{a=1}^{N} \frac{z_{a, k} S_{a, 1}}{N} \eta_{1}-\sum_{a=1}^{N} \frac{z_{a, k} S_{a, 2}}{N} \eta_{2} \\
\hat{Q}\left(\eta_{1}, \eta_{2}\right) & =\sum_{k=1}^{K}\left(\min \left\{0, \hat{m}_{k}(\eta)\right\}\right)^{2}
\end{aligned}
$$

and I can find the estimate of the identified set by solving:

$$
\hat{\Theta}=\arg \min _{\eta \in \bar{\Theta}^{C}} \hat{Q}(\eta)
$$

In my application, $\mathrm{K}$ is equal to 4 and the instruments $z_{a, k}$ are indicator variables for the four types of moment inequalities described in Section 3.3. The first two types of moment inequalities provide me with upper bounds and the remaining two with lower bounds. When I need to reset the price optimally in a counterfactual, I change the price of a product by the amount that prices of that product are usually changed, in most cases 10 cents.

\section{Confidence Intervals}

I follow Pakes et al. (2011) approach to inference and I construct confidence intervals for the identified set. This section draws extensively from Holmes (2010) and Morales et al. (2011). Let $\mathrm{K}$ be the number of moment inequalities and $\tilde{w}_{a}$ be a $3 K \times 1$ vector that contains the moment inequality variables for deviation $a$, where the first $K$ elements contain $z_{a, k} \Delta r_{a}$, the second $K$ elements contain $S_{a, 1} \eta_{1}$ and the third $K$ elements contain $S_{a, 2} \eta_{2}$. The sample mean of $\tilde{w}_{a}$ over the $N$ observed deviations is:

$$
\bar{w}_{a}=\sum_{a=1}^{N} \frac{\tilde{w}_{a}}{N}
$$

and it has variance-covariance matrix equal to $\Sigma / N$, where $\Sigma$ is the variance-covariance matrix of the distribution of $\tilde{w}_{a}$. Pakes et al. (2011) explain how to simulate inner 
and outer confidence intervals for the identified set by calculating sample analogs of the identified set for simulated moments. Let's start from the inner confidence interval. We construct $S$ simulations of the moment inequalities, drawing a random column vector $w_{s}$ with $3 K$ elements from the normal distribution with mean $\bar{w}$ and variance covariance $\hat{\Sigma} / N$. Then we can derive moment inequalities from $w_{s}$ by decomposing it in three components of $K$ elements each and rearranging the vectors as in equation (7):

$$
w_{1, s} \geq w_{2, s} \eta_{1}+w_{3, s} \eta_{2}
$$

Define $\tilde{Q}^{\text {inner }}$ as in (13) and calculate bounds for the parameters $\eta_{1}$ and $\eta_{2}$. The inner confidence interval for each bound consists in the $\alpha / 2$ and $1-\alpha / 2$ percentiles of the distribution of the simulated bounds. In order to compute the outer confidence intervals I'll follow the same procedure, but instead of (15) we have:

$$
w_{1, s} \geq w_{2, s} \eta_{1}+w_{3, s} \eta_{2}+\kappa
$$

where $\kappa$ is evaluated at the actual data and at the estimated bounds and represents the "slack" in the nonbinding moment inequalities:

$$
\kappa=\max \left\{0, \sum_{a=1}^{N} \frac{z_{a, k} \Delta r_{a}}{N}-\sum_{a=1}^{N} \frac{z_{a, k} S_{a, 1}}{N} \hat{\eta}_{1}-\sum_{a=1}^{N} \frac{z_{a, k} S_{a, 2}}{N} \hat{\eta}_{2}\right\}
$$

The deviations I use in the estimations are not statistically independent, because they are derived from $M=808$ store-week observations. In order to control for this interdependence I follow the subsampling procedure described by Holmes (2010). Let's draw a store-week subsample of size $b=M / 3$ from the $M=808$ store-week observations and then let's define the deviation subsample as the set of observations that belong to the store-week subsample. I repeat this procedure and calculate each time the mean $\bar{w}_{b}$. Using the different subsample we can estimate the variance covariance matrix of $\bar{w}_{b}$ and then we can use:

$$
\operatorname{Var}\left(\bar{w}_{M}\right)=\frac{b}{M} \operatorname{Var}\left(\bar{w}_{b}\right)
$$

as an estimate of the variance-covariance matrix of the distribution of $\bar{w}_{a}$. 


\section{Data Description}

\subsection{Dominick's Finer Foods}

To implement my estimation strategy, I need data on quantities, prices and costs of the products sold by a multi-product firm over some period of time. Following Goldberg and Hellerstein (2013), I use the dataset collected by the Kilts Center of Marketing at Chicago Booth on the supermarket chain Dominick's Finer Foods. My dataset consists of weekly observations of quantities, prices and costs of 37 upc-level beer products sold by the supermarket chain in the Chicago area from 6 June, 1991 to 6 June, 1995. ${ }^{21}$ The dataset contains data on around 100 stores in the Chicago area, but prices are not different in each store; stores were divided by the management into 4 price groups, within which prices charged were the same. Data on product characteristics come from a Consumer Reports study conducted in 1996.

Eichenbaum et al. (2012) shows that the high frequency of small price changes in some retail supermarket data and in the BLS CPI microdata could be due to measurement error; they show that when prices are derived from measures of revenues and quantities sold and there are customer-specific sales, small changes in the composition of customers can produce measurement error in price changes and bias towards finding a higher frequency of small price changes. Their critique does not apply to my data for several reasons; first, the Dominick's dataset contains retail prices and therefore I do not derive prices from revenues and quantities sold. Second, I focus only on regular price changes and I integrate the information on sales provided by the supermarket with a visual check of the data to make sure that the regular price changes in my data do not include temporary promotional price changes. Third, my dataset was collected in the first half of the 1990s, when the customer-specific promotion plans were not as prevalent as they are today.

\subsection{Preliminary evidence on economies of scope}

Before showing that moment inequalities estimation uncovers significant economies of scope in price setting, I would like first to present some reduced-form preliminary evidence of it. Table 1 describes the frequency of price changes in my dataset by reporting the median frequency of regular price changes.

\footnotetext{
${ }^{21}$ Some upc-level products had the same exact pricing and sales pattern throughout the dataset and were therefore treated as one product in the analysis.
} 
Table 1: Median Frequencies of Regular Price Changes

Probability Duration in quarters

Unconditional

0.025

3.1

Conditional on at least one price change for

0.11

0.7 other products

The unconditional median price duration is around 3 quarters, the same reported by Eichenbaum et al. (2010) for their measure of reference prices and also very similar to the price duration in the BLS microdata, as Nakamura and Steinsson (2008) show. Table 1 shows also the median frequency of price changes conditional on existence of at least one price change in the category of products: the probability of a price change for product $j$ increases if I condition on the existence of at least one price change in the category, excluding product $j$.

Table 2: Economies of Scope

\begin{tabular}{lc}
\hline & \\
\hline & $0.13^{* * *}$ \\
& {$[0.02]$} \\
& \\
Awn markup gap & $1.43^{* * *}$ \\
& {$[0.11]$} \\
& $\mathrm{X}$ \\
Product FE & $\mathrm{X}$ \\
Quarter FE & 20,941 \\
Observations & 0.25 \\
Pseudo- $R^{2}$ & \\
\hline The coefficients reported are marginal effects. & $* * * \mathrm{p}<0.01, * * \mathrm{p}<0.05, * \mathrm{p}<0.1$ \\
\end{tabular}

Following Midrigan (2011), I estimate a probit model where the dependent variable is a dummy variable equal to 1 if there is a regular price change and equal to 0 otherwise. The independent variables are the own markup gap and the average markup gap of the other products in the category; the markup gap is computed as the absolute value of the $\log$ difference between the last regular markup and the average markup for the product over the time period of the analysis. As shown in Table 2, the higher the own markup gap the higher the probability of a price change. Some reduced form evidence of economies of 
scope in price setting is given by the positive, large and statistically significant coefficient on the average markup gap of the other goods in the category: if the markup of other products is out of line, the probability of a price change for a product in the same category increases. In the probit regressions, I include both quarter and product fixed effects as controls.

\section{Results}

\subsection{First Stage}

Table 3: Logit Model

\begin{tabular}{|c|c|c|}
\hline & $\begin{array}{l}(1) \\
\text { OLS }\end{array}$ & $\begin{array}{l}(2) \\
\text { IV }\end{array}$ \\
\hline \multirow[t]{2}{*}{ price } & $-0.554^{* * *}$ & $-1.190^{* * *}$ \\
\hline & {$[0.009]$} & {$[0.110]$} \\
\hline \multirow{2}{*}{$\begin{array}{l}\text { time FE } \\
\text { product } \mathrm{FE}\end{array}$} & $\mathrm{X}$ & $\mathrm{X}$ \\
\hline & $\mathrm{X}$ & $\mathrm{X}$ \\
\hline \multirow{2}{*}{$\begin{array}{l}\text { Observations } \\
R^{2}\end{array}$} & 29,896 & 29,896 \\
\hline & 0.844 & 0.803 \\
\hline \multicolumn{3}{|c|}{ First Stage } \\
\hline$R^{2}$ & \multicolumn{2}{|c|}{0.9864} \\
\hline F-statistic & \multicolumn{2}{|c|}{38.57} \\
\hline
\end{tabular}

Table 3 reports the estimated parameters for the logit model. The simple logit model is estimated by regressing $\ln \left(s_{j}\right)-\ln \left(s_{0}\right)$ on price and product characteristics. I estimate both a simple OLS regression and then I instrument price to control for endogeneity with the instruments described above. The coefficients on price are negative and statistically significant. In the regression, I include as controls product and time fixed effects, brand dummies, a sales dummy and product characteristics. Finally, the F-test on the joint significance of the excluded instruments are significantly higher than the threshold used commonly in the literature of 10 . 
Table 4: Full Model

\begin{tabular}{lcc}
\hline & $(1)$ & $(2)$ \\
& mean & std dev \\
\hline \multirow{2}{*}{ price } & $-5.425^{* * *}$ & $2.056^{* * *}$ \\
& {$[1.780]$} & {$[0.0781]$} \\
alcohol & -0.010 & $0.703^{*}$ \\
& {$[0.008]$} & {$[0.421]$} \\
time FE & $\mathrm{X}$ \\
product FE & $\mathrm{X}$ \\
Observations & \multicolumn{2}{c}{29,896} \\
MD weighted $R^{2}$ & \multicolumn{2}{c}{0.14} \\
\hline \multicolumn{2}{c}{$* * * \mathrm{p}<0.01,{ }^{* *} \mathrm{p}<0.05,^{*} \mathrm{p}<0.1$}
\end{tabular}

Table 4 reports the results from the full model. ${ }^{22}$ The coefficient on price is negative and statistically significant, as expected. Table 5 contains the median own- and cross-price elasticities of a sample of five products from the dataset; ${ }^{23}$ own-price elasticities are all as expected negative and lower than -1, whereas the cross-price elasticities are positive and vary depending on the degree of substitution between the two products as estimated by the random coefficients demand model from the data.

Table 5: Median Own and Cross Elasticities

\begin{tabular}{ccccc}
\hline-13.95 & 0.31 & 0.07 & 0.10 & 0.26 \\
0.04 & -31.71 & 0.08 & 0.18 & 0.46 \\
0.05 & 0.41 & -22.37 & 0.12 & 0.34 \\
0.05 & 0.55 & 0.08 & -32.75 & 0.48 \\
0.04 & 0.53 & 0.08 & 0.17 & -32.75 \\
\hline
\end{tabular}

\footnotetext{
${ }^{22} \mathrm{~A}$ constant and a sales dummy are included in the estimation, but not shown. Product and time fixed effects are also included.

${ }^{23}$ The full table of the elasticities for all the 37 products is available upon request. I define a product as a upc-level product, whereas most of the previous literature aggregated upc-level products up to the brand-level and defined a product as a serving of a brand of beer; in my study, the usual strategy would not be warranted as the pricing decision is made on the upc-level product and upc-level products of different size have different pricing paths even if they belong to the same brand. Because of how I define market share, products in my dataset have small market shares and it can partly explain why I find larger price elasticities than the previous literature.
} 


\subsection{The Size of Menu Costs}

In Table 6, I summarize the results of the moment inequalities estimation of the menu costs. $^{24}$ Section 3.3 describes the four types of moment inequalities I use to estimate bounds for the menu costs. There are 136 price deviations for the first type of inequality, 537,625,521 for the second, 692 for the third and 105 for the fourth. Since there are too many alternative scenarios for the second type of moment inequality, I will need to restrict the sample to make the estimation computationally feasible.

Table 6: Estimated Bounds in $\$$

\begin{tabular}{lcccccccc}
\hline & \multicolumn{2}{c}{ Specification I } & \multicolumn{2}{c}{ Specification II } & \multicolumn{2}{c}{ Specification III } & \multicolumn{2}{c}{ Specification IV } \\
& Lower & Upper & Lower & Upper & Lower & Upper & Lower & Upper \\
Common MC $\left(\eta_{1}\right)$ & 0 & 880.70 & 136.49 & 851.25 & 283.45 & 958.80 & 288.97 & 860.87 \\
Item MC $\left(\eta_{2}\right)$ & 65.55 & 375.50 & 65.55 & 125.88 & 36.70 & 36.70 & 33.34 & 33.34 \\
\hline
\end{tabular}

I estimate four specifications. In "Specification I", I sample from the pool of possible price deviations for the second inequality. ${ }^{25}$ In the other specifications, I restrict my sample of deviations to those that should give me tighter bounds for the estimated parameters. The smaller the change in the cost of a product, the smaller the loss in profits if the price of the product is not changed; for this reason, focusing on observations of a price change with a small cost change should give me tighter bounds. In "Specification II", I restrict the sample only to those deviations with a non-zero change in cost in absolute value smaller than 5\%. In "Specification III", I restrict the sample to those deviations with no change in the costs; you would expect very small "item menu cost" if the manger changes the prices of products when their costs do not change. In Table 2, I show that the own markup gap has predictive power for price changes; in "Specification IV", I use this empirical fact by restricting the sample only to those deviations with a markup gap lower than the median markup gap observed for a price change in the sample.

As shown in Tables 6, "Specification I" delivers bounds that are too wide and include zero for the "common menu cost". The other three specifications deliver tighter bounds and show the importance of the "common menu cost"; in "Specification III" and "Specification IV", there are no values of the "item menu cost" that verify all constraints, therefore the moment inequalities estimation provides point estimates. Figure 1 visually displays the results from "Specification II", the only one that identifies a set of parameters

\footnotetext{
${ }^{24}$ In the moment inequality estimation I use a weekly discount factor, $\gamma$ in the model, consistent with an annual interest rate of 5\%, which is the average interest rate in the US in the period 1991-1995.

${ }^{25}$ I resampled a few times to make sure that the results were robust
} 
verifying all the constraints; the first type of inequality delivers the green line in the figure, the second type delivers the red line, the third type delivers the purple line and finally the fourth type delivers the light blue line.

Figure 1: Bounds in Specification II

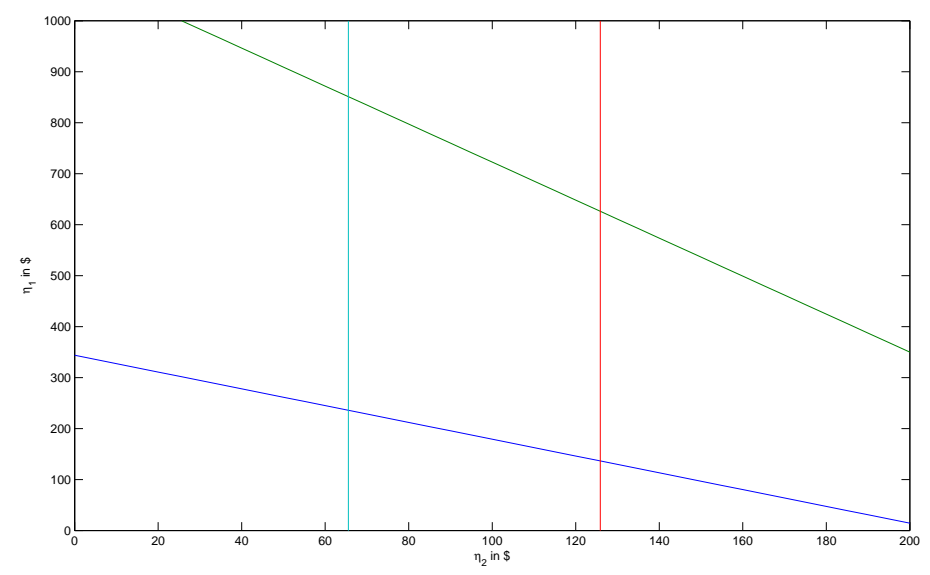

I computed the confidence intervals as described in Section 4; as Table 7 shows, both the inner and outer confidence intervals for "Specification II" and "Specification IV" are very close to the estimated bounds and are bounded away from zero; "Specification III" provides wider bounds that occasionally include also zero. ${ }^{26}$

Table 7: Confidence Intervals

\begin{tabular}{lcccccccc}
\hline & \multicolumn{3}{c}{ Specification I } & \multicolumn{2}{c}{ Specification II } & \multicolumn{2}{l}{ Specification III } & \multicolumn{2}{l}{ Specification IV } \\
Confidence Intervals $\eta_{1}$ & & & & & & & & \\
PPHI Inner (95\%) & 0 & 895.88 & 95.01 & 913.70 & 164.91 & $1,962.56$ & 288.96 & 860.88 \\
PPHI Outer (95\%) & 0 & 895.88 & 95.01 & 913.70 & 0 & $6,024.32$ & 288.96 & 860.88 \\
& & & & & & & & \\
Confidence Intervals $\eta_{2}$ & & & & & & & & \\
PPHI Inner (95 \%) & 64.39 & 382.34 & 62.70 & 127.31 & 0 & 36.70 & 33.34 & 33.34 \\
PPHI Outer (95\%) & 64.39 & 382.34 & 62.70 & 127.31 & 0 & 36.70 & 33.34 & 33.34 \\
\hline
\end{tabular}

In order to understand the relevance of the estimated menu costs, it is useful to relate them to revenues and profits; in Table 8, I report that the expenditure due to menu costs represent, in "Specification II", between $0.26 \%$ and $0.59 \%$ of revenues or between

\footnotetext{
${ }^{26}$ Unfortunately, it would be computationally unfeasible to compute confidence intervals including the first stage uncertainty; since the second stage confidence intervals are very tight for both "Specification II" and "Specification IV", I am less concerned that including the first stage uncertainty would make a difference.
} 
$2.84 \%$ and $6.36 \%$ of gross margin or between $13.08 \%$ and $29.32 \%$ of net margins; very similar results come from "Specification III" and "Specification IV". ${ }^{27}$ Table 8 also shows how much each type of menu cost contribute to the total amount paid to change prices; the "common menu cost" $\eta_{1}$ has an important role in all specifications and, in the most restrictive ones, accounts for between $65 \%$ and $85 \%$ of the total menu costs.

Table 8: Estimated Bounds as a percentage of Revenues and Profits

\begin{tabular}{lcccccc}
\hline & \multicolumn{2}{c}{ Specification II } & \multicolumn{2}{c}{ Specification III } & \multicolumn{2}{c}{ Specification IV } \\
& Lower & Upper & Lower & Upper & Lower & Upper \\
Revenues & $0.26 \%$ & $0.59 \%$ & $0.22 \%$ & $0.55 \%$ & $0.22 \%$ & $0.50 \%$ \\
Gross Margin & $2.84 \%$ & $6.36 \%$ & $2.40 \%$ & $6.01 \%$ & $2.35 \%$ & $5.41 \%$ \\
Net Margin & $13.08 \%$ & $29.32 \%$ & $11.05 \%$ & $27.71 \%$ & $10.82 \%$ & $24.94 \%$ \\
& & & & & & \\
$\quad$ Contribution of $\eta_{1}$ & $20 \%$ & $74 \%$ & $64 \%$ & $85 \%$ & $66 \%$ & $85 \%$ \\
$\quad$ Contribution of $\eta_{2}$ & $26 \%$ & $80 \%$ & $15 \%$ & $37 \%$ & $15 \%$ & $34 \%$ \\
\hline
\end{tabular}

\section{Previous Estimates of Menu Costs}

The previous literature provides some evidence supporting the existence of menu costs. Most previous estimations have been based on narrative observational evidence, rather than statistical analysis, with the exception of Slade (1998) and Aguirregabiria (1999). Furthermore all previous empirical work, with the exception of Lach and Tsiddon (2007), Bhattarai and Schoenle (2012) and Anderson et al. (2012), was concerned with the price change of a single product and did not consider the interactions of multi-product price setting.

Levy et al. (1997) use store-level data from five multi-store supermarket chains to study the exact process of changing prices. They find that the menu costs average $\$ 105,887$ per year per store, which represents $0.7 \%$ of revenues or $35.2 \%$ of net margins, and amounts to $\$ 0.52$ per price change. ${ }^{28}$ By interviewing supermarket managers the authors were also able to understand the sources of the menu costs that they estimated: labor costs of changing prices, costs of printing and delivering new price tags, the costs of mistakes made during the price change process, the cost of in-store supervision of the price change process. The main drawback of the Levy et al. paper is that the estimation is based on

\footnotetext{
${ }^{27}$ Net margins are calculated as $2 \%$ of revenues as suggested by Montgomery (1994).

${ }^{28}$ It must be noted that Levy et al. (1997) does not exclude promotional price changes from the computation of total menu costs.
} 
narrative observational evidence on the physical costs of price adjustment alone. Zbaracki et al. (2004) claim that the physical costs of changing prices are only one component of menu costs and they identify and measure managerial costs and customer costs using data on a industrial firm. They find that both managerial costs and customer costs are more important than the physical costs of price changing. They estimate that menu costs amount to $1.22 \%$ of revenues and $20.03 \%$ of net margins, or between $\$ 22.52$ and $\$ 121.64$ per price change.

In order to overcome the limits of direct measurements, a few papers perform a structural estimation of menu costs. Slade (1998) estimates menu costs with GMM by developing a discrete-choice dynamic programming model that includes both fixed and variable costs of adjusting prices. ${ }^{29}$ She uses weekly retail prices, factor prices and sales of three brands of saltine crackers sold by four chains of grocery stores in a small US town over the period of two years. It is found that the variable adjustment cost parameter is not statistically significantly different from zero, whereas the fixed cost parameter is estimated with precision. The average cost per price change is $\$ 2.72$, of which $\$ 2.55$ is fixed. Aguirregabiria (1999) develops a dynamic discrete-choice model, in which the retailer has to decide retail prices and orders to suppliers and faces fixed costs both for adjusting prices and for buying supplies. The retailer has to order supplies before knowing the demand shock, therefore the demand may end up exceeding the retailer's inventories. This generates a cyclical price behavior with frequent and short lived price reductions, which mimics the frequency of real life sales promotions. Slade (1998) and Aguirregabiria (1999) both use data collected in supermarkets, which are the stereotypical multi-product firm; however, they model supermarkets as a single-product firm, as the large dimension of the choice set in a multi-product setting makes the estimation computationally infeasible with the traditional discrete choice methods that they employ. By using moment inequalities, I am able to solve this dimensionality problem and therefore estimate a dynamic multi-product firm model.

Nakamura and Zerom (2010) and Goldberg and Hellerstein (2013) provide estimates of menu cost in their empirical analysis of the puzzle of incomplete exchange rate passthrough, i.e. the incomplete transmission of exchange rate fluctuations to prices for exported and imported goods. ${ }^{30}$ There are many possible candidate factors that can explain this phenomenon and fixed costs of price adjustment is a leading candidate. Nakamura and

\footnotetext{
${ }^{29}$ Slade (1998) and Aguirregabiria (1999) use the estimation algorithm developed by Hotz and Miller (1993).

${ }^{30}$ The incomplete exchange rate pass-through puzzle is well documented by Engel (1999), Parsley and Wei (2001), Goldberg and Campa (2008) and Gopinath et al. (2010)
} 
Zerom (2010) produce some estimates for menu costs through a calibration exercise and find that menu costs do not explain much of the exchange rate pass-through. On the other hand, Goldberg and Hellerstein (2013) use a revealed preference approach and find that menu costs contribute to explain about a third of the incomplete exchange pass-through in their dataset.

Finally, Lach and Tsiddon (2007), Bhattarai and Schoenle (2012) and Anderson et al. (2012) provide some suggestive evidence for economies of scope in price setting. In all price datasets a substantial fraction of price changes are very small and this observation challenges traditional menu cost models where firms change prices only when their current price is far from the optimal price. Lach and Tsiddon (2007) claim that small price changes are consistent with multi-product firms facing store-specific menu costs that generate economies of scope in price setting. They show that in their dataset of Israeli grocery stores small average price changes are very infrequent and the smaller the individual price change in a store the larger the price change in the remaining products sold by the same store. Bhattarai and Schoenle (2012) analyze microdata on US producer prices and find evidence consistent with the existence of a firm-specific menu cost. They establish three main empirical facts; first, firms that sell more goods adjust prices more frequently, but the price adjustments are smaller on average. Second, firms synchronize the price changes across products. Third, the within firm syncronization of price changes is an increasing function in the number of goods. Anderson et al. (2012) analyze the "uniform pricing" policy that requires all the variants of a product to have the same price and show that prices of products with more variants are more sticky.

\section{Conclusion}

In menu cost models firms face fixed costs of price adjustment and therefore change prices less frequently than they otherwise would. Klenow and Kryvtsov (2008) and Alvarez et al. (2013) present evidence that menu cost models are overall consistent with the empirical facts on price adjustment. On the other hand, Caplin and Spulber (1987) and Golosov and Lucas (2007) challenge the ability of menu cost models to produce high degrees of monetary non-neutrality. Recently, a new literature in macroeconomics revived the interest in menu cost models by showing that with the introduction of price setting interactions menu cost models are able to match the empirical facts better and to produce real effects of monetary policy. For instance, Midrigan (2011) shows that, if firms sell many products

and face economies of scope in price setting, the selection effect described by Golosov and 
Lucas (2007) is substantially weakened.

In this paper, I present evidence that menu costs exist and are substantial. I estimate two types of menu costs: costs that are independent of the number of items that change prices and costs that are incurred at each items price change and I find that both menu costs are statistically and economically significant. My findings provide empirical support for the second-generation state dependent pricing models and in particular for those models that rely on economies of scope in price setting.

\section{References}

[1] Aguirregabiria, M.E. (1999), "The Dynamics of Markups and Inventories in Retailing Firms", Review of Economic Studies, 66, 275-308.

[2] Alvarez, F and F. Lippi (2012), "Price setting with menu cost for multi-product firms", NBER Working Papers 17923.

[3] Alvarez, F, M. Gonzalez-Rozada, A. Neumeyer and M. Beraja (2013), "From Hyperinflation to Stable Prices: Argentina's Evidence on Menu Cost Models", working paper.

[4] Anderson, E., N. Jaimovich and D. Simester (2012), "Price Stickiness: Empirical Evidence on the Menu Cost Channel", working paper.

[5] Barro, R.J. (1972), "A Theory of Monopolistic Price Adjustment", Review of Economic Studies, 39, 17-26.

[6] Basuroy, S., M.K. Matrala and R.G. Walters (2001), "The Impact of Category Management on Retailer Prices and Performance: Theory and Evidence", Journal of Marketing, 65, 16-32

[7] Berry, S., J. Levinsohn and A. Pakes (1995), "Automobile prices in market equilibrium", Econometrica 63(4), 841-890.

[8] Besanko, D., JP. Dubé and S. Gupta (2005), "Own-Brand and Cross-Brand Retail Pass-Through", Marketing Science, 24, 123-137. 
[9] Bhattarai, S. and R. Schoenle (2012), "Multiproduct Firms and Price-Setting: Theory and Evidence from US Producer Prices", working paper.

[10] Bils, M. and P.J. Klenow (2004), "Some Evidence on the Importance of Sticky Prices", Journal of Political Economy, 112(5), 947-985.

[11] Bolton, R.N. and V. Shankar (2003), "An Empirically Derived Taxonomy of Retailer Pricing and Promotion Strategies", Journal of Retailing, 79, 213224

[12] Calvo, G. A. (1983), "Staggered Prices in a Utility-Maximizing Framework", Journal of Monetary Economics, 12, 383398.

[13] Campa, J.M. and L.S. Goldberg (2008), "Pass-Through of Exchange Rates to Consumption Prices: What Has Changed and Why?", NBER Chapters, in: International Financial Issues in the Pacific Rim: Global Imbalances, Financial Liberalization, and Exchange Rate Policy, 139-176

[14] Caplin A.S. and D.F. Spulber (1987), "Menu Costs and the Neutrality of Money", Quarterly Journal of Economics, 102(4) 703-726.

[15] Chintagunta, P.K., J.P. Dubé and V. Singh (2003), "Balancing Profitability and Customer Welfare in a Supermarket Chain", Quantitative Marketing and Economics, $1,11147$.

[16] Christiano, L.J., M. Eichenbaum and C.L. Evans (1996), "The Effects of Monetary Policy Shocks Evidence from the Flow of Funds", The Review of Economics and Statistics, 78(1), 1634.

[17] Cochrane, J.H. (1998), "What Do the VARs Mean? Measuring the Output Effects of Monetary Policy", Journal of Monetary Economics, 41(2), 277-300.

[18] Dotsey, M., M. King and A. Wolman (1999), "State-Dependent Pricing and the General Equilibrium Dynamics of Money and Output", Quarterly Journal of Economics, $114,655-690$.

[19] Dotsey, M., M. King and A. Wolman (2009), "Inflation and Real Activity with Firm-level Productivity Shocks: a Quantitative Framework", working paper.

[20] Dreze, X., S.J. Hoch and M.E. Purk (1994), "EDLP, Hi-Lo, and Margin Arithmetic", Journal of Marketing, 58, 1629. 
[21] Eichenbaum, M., N. Jaimovich, and S. Rebelo (2011), "Reference Prices, Costs, and Nominal Rigidities", American Economic Review, 101, 234262.

[22] Eichenbaum, M., N. Jaimovich, S. Rebelo and J. Smith (2012), "How Frequent are Small Price Changes", working paper.

[23] Engel, C. (1999), "Accounting for U.S. Real Exchange Rate Changes", Journal of Political Economy, 107(3), 507-538.

[24] Gagnon, E. (2009), "Price Setting During Low and High Inflation: Evidence from Mexico", Quarterly Journal of Economics, 124(3), 1221-1263.

[25] Gertler M and J. Leahy (2008), "A Phillips Curve with an Ss Foundation", Journal of Political Economy, 116(3), 533-572.

[26] Goldberg, P.K. and R. Hellerstein (2013), "A Structural Approach to Identifying the Sources of Local-Currency Price Stability", Review of Economic Studies, 80, 175-210.

[27] Golosov, M. and R.E. Lucas Jr (2007), "Menu Costs and Phillips Curves", Journal of Political Economy, 115(2), 171-199.

[28] Gopinath G., O. Itskhoki and R. Rigobon (2010), "Currency Choice and Exchange Rate Pass-through", American Economic Review, 100(1), 304-3-D.

[29] Hendel, I., and A. Nevo (2006), "Measuring the Implications of Sales and Consumer Inventory Behavior", Econometrica 74(6), 1637-1673.

[30] Holmes, T. J. (2011), "The Diffusion of Wal-Mart and Economies of Density", Econometrica, 79(1), 253-302.

[31] Hosken, D., D. Matsa and D. Reiffen (2000), "How do Retailers Adjust Prices? Evidence from Store-Level Data", FTC working paper 230.

[32] Kackmeister A. (2007), "Yesterday's Bad Times Are Toda's Good Old Times: Retail Price Changes Are More Frequent Today Than in the 1890s", Journal of Money, Credit and Banking, 39(8), 1987-2020.

[33] Kadiyali V., P. Chintagunta and N. Vilcassim. (2000), "Manufacturer-Retailer Channel Interactions and Implications for Channel Power: An Empirical Investigation of Pricing in a Local Market", Marketing Science, 19(2), 127-148. 
[34] Kehoe P.J. and V. Midrigan (2010), "Prices Are Sticky After All", NBER Working Papers 16364.

[35] Klenow P.J. and O. Kryvtsov (2008), "State-Dependent or Time-Dependent Pricing: Does It Matter for Recent U.S. Inflation?", Quarterly Journal of Economics, 123(3), 863-904.

[36] Lach S. and D. Tsiddon (2007), "Small Price Changes and Menu Costs", Managerial and Decision Economics, 28, 649-656.

[37] Mankiw N.G. (1985), "Small Menu Costs and Large Business Cycles: A Macroeconomic Model of Monopoly", Quarterly Journal of Economics 100, 529-537.

[38] Montgomery, A.L. (1994), "The Impact of Micro-Marketing on Pricing Strategies", $\mathrm{PhD}$ thesis.

[39] Midrigan, V. (2011), "Menu Costs, Multi-Product Firms and Aggregate Fluctuations", Econometrica, 79(4), 1139-1180

[40] Montgomery, A. (1997), "Creating Micro-Marketing Pricing Strategies Using Supermarket Scanner Data", Marketing Science, 16(4), 315-337.

[41] Morales E., G. Sheu and A. Zahler (2011), "Gravity and Extended Gravity: Estimating a Structural Model of Export Entry", working paper.

[42] Nakamura E. and J. Steinsson (2008), "Five Facts About Prices: A Reevaluation of Menu Cost Models", Quarterly Journal of Economics, 123(4), 1415-1464.

[43] Nakamura E. and J. Steinsson (2010), "Monetary Non-Neutrality in a Multisector Menu Cost Model", Quarterly Journal of Economics, 125(3), 961-1013.

[44] Nakamura E. and D. Zerom (2010), "Accounting for Incomplete Pass-Through", Review of Economic Studies, 77(3), 1192-1230.

[45] Nevo, A. (2000), "A practitioner's guide to estimation of random-coefficients logit models of demand", Journal of Economics and Management Strategy, 9(4), 513-548

[46] Nevo, A. (2001), "Measuring market power in the ready-to-eat cereal industry", Econometrica, 69(2), 307-342.

[47] Pakes, A., J. Porter, K. Ho, and J, Ishii. (2011), "Moment Inequalities and Their Application", working paper 
[48] Pakes, A. (2010), "Alternative Models for Moment Inequalities", Econometrica, 78(6), 1783-1822.

[49] Parsley, D. C., and S.J. Wei (2001): "Explaining the border effect: the role of exchange rate variability, shipping costs and geography", Journal of International Economics, 55, 87-105.

[50] Peltzman, S. (2000), "Prices rise faster than they fall". Journal of Political Economy,108(3), 466-502.

[51] Romer, C. and D. Romer (2004), "A New Measure of Monetary Shocks: Derivation and Implications", American Economic Review, 94(4), 1055-1084.

[52] Sheshinski, E. and Y. Weiss (1977), "Inflation and Costs of Price Adjustment", Review of Economic Studies, 44(2), 287-303.

[53] Sheshinski, E. and Y. Weiss (1992), "Staggered and Synchronized Price Policies Under Inflation: The Multiproduct Monopoly Case", Review of Economic Studies, 59, 331-359.

[54] Slade, M.E. (1995), "Product Market Rivalry with Multiple Strategic Weapons: An Analysis of Price and Advertising Competition", Journal of Economics and Management Strategy, 4, 445-476.

[55] Slade, M.E. (1998), "Optimal Pricing with Costly Adjustment: Evidence from Retail-Grocery Prices", Review of Economic Studies, 65, 87-107.

[56] Sudhir, K. (2001), "Structural Analysis of Manufacturer Pricing in the Presence of a Strategic Retailer", Marketing Science, 20(3), 244-264.

[57] Taylor, John B. (1980), "Aggregate Dynamics and Staggered Contracts", Journal of Political Economy, 88, 123.

[58] Villas-Boas S.B. (2007), "Vertical Relationships between Manufacturers and Retailers: Inference with Limited Data", Review of Economic Studies, 74, 625-652.

[59] Woodford M. (2003), "Interest and Prices: Foundations of a Theory of Monetary Policy", Princeton University Press. 